\title{
Aportación de la Arqueoantropología a la interpretación de la dinámica sepulcral de las tumbas megalíticas de Cameros (La Rioja, España)
}

\author{
Contribution of Archaeoanthropology to the interpretation of the funerary use of Cameros \\ megalithic graves (La Rioja, Spain)
}

\author{
Teresa Fernández-Crespo $(*)(* *)$
}

\section{RESUMEN}

Se intentan reconstruir los modos de uso funerario neolíticos y calcolíticos de los principales megalitos de Cameros (La Rioja): Peña Guerra II, Collado del Mallo, Fuente Morena y Collado Palomero I. El análisis del registro combina los diversos parámetros arqueoantropológicos (perfiles osteológicos, conexiones anatómicas, remontajes, alteraciones tafonómicas, manipulaciones) con los datos de campo. Los resultados muestran una realidad compleja donde la inhumación primaria parece predominante, acompañada de labores de reacomodo (nidos de cráneos, haces de huesos) y tal vez de ciertas limpiezas puntuales. No obstante, las deposiciones secundarias, en forma o no de cremaciones, pudieron desempeñar también un papel relevante.

\footnotetext{
ABSTRACT

We attempt to reconstruct the Neolithic and Chalcolithic funerary use of the main megalithic monuments from Cameros (La Rioja): Peña Guerra II, Collado del Mallo, Fuente Morena and Collado Palomero I. The record is analysed through a combination both of diverse archaeoanthropological parameters (osteological profile, anatomical connection, bone refitting, taphonomic alterations, bone handling) and of field data. The results suggest a complex reality where primary inhumations predominate,

(*) Dpto. de Genética, Antropología Física y Fisiología Animal, Universidad del País Vasco (UPV/EHU). B ${ }^{\circ}$ Sarriera $\mathrm{s} / \mathrm{n}$. 48940 Leioa. España. Correo e.: teresa.fernandezc@ehu.es

(**) Research Laboratory for Archaeology and the History of Art, University of Oxford. South Parks Road. OX1 3QY Oxford. United Kingdom.

Correo e.: teresa.fernandez-crespo@rlaha.ox.ac.uk

Recibido: 13-II-2015; aceptado: 4-V-2015.
}

but where spatial arrangements (nests of skulls and bundles of long bones) and perhaps some isolated bone removal also occurred. Secondary depositions, whether in the form of cremation or not, may also have played a role.

Palabras clave: Arqueoantropología; Prácticas funerarias; Tumbas megalíticas; Neolítico avanzado-Calcolítico final; Cameros; Valle del Ebro; Península Ibérica.

Key words: Archaeoanthropology; Funerary practices; Megalithic graves; Late Neolithic-Late Chalcolithic; Cameros; Ebro valley; Iberian Peninsula.

\section{INTRODUCCIÓN}

Los contextos sepulcrales representan una problemática muy particular en los estudios arqueológicos ya que sólo a través de una aproximación que privilegie la reconstitución conjunta de los gestos funerarios y los procesos tafonómicos puede llegar a reconocerse su funcionamiento (Crubézy et al. 1990; Duday 2005). Obviamente, lo ideal es que estas observaciones sean recogidas directamente sobre el terreno. Sin embargo, en la mayoría de los casos los especialistas en restos humanos han de enfrentarse al estudio de colecciones ya excavadas (muchas veces hace décadas), lo que supone una importante limitación de partida. Recomponer las condiciones del depósito exige del antropólogo contrastar los resultados obtenidos en el laboratorio con la documentación gráfica y escrita generada en los trabajos de campo, muchas veces en la confianza de que las apreciaciones del arqueólogo 
sean correctas (Duday et al. 1990). Pese a esta coyuntura habitual, los restos óseos -incluso ya en parte descontextualizados- siguen irguiéndose como el resultado material más directo de los tratamientos practicados y los procesos tafonómicos acaecidos en las sepulturas. Sometidos a un examen sistemático pueden aportar información muy relevante, a veces incluso detallada, sobre los comportamientos funerarios (Fernández-Crespo 2010).

Bajo esas premisas, este estudio pretende arrojar nuevos datos sobre la dinámica sepulcral de las tumbas de la estación megalítica riojana de Cameros a través de una serie de protocolos definidos por la Anthropologie de terrain (Duday et al. 1990). Las tumbas seleccionadas al efecto (Peña Guerra II, Collado de Mallo, Fuente Morena y Collado Palomero I) fueron excavadas a finales del siglo pasado utilizando una metodología moderna que permitió la recuperación y registro sistemáticos de todos los restos humanos y culturales (1). Prueba de ello es la amplia documentación disponible sobre los contextos y materiales exhumados, la cual permite completar y afinar el discurso ofrecido por la Antropología física (2).

\section{CONTEXTO}

El grupo megalítico de Cameros se sitúa en el tramo medio de la Cuenca del Ebro, en el sur de la actual Comunidad Autónoma de La Rioja (Fig. 1). Es una estación serrana, cuyas tumbas se localizan a gran altitud (950-1.240 m.s.n.m.). Resulta complicado encontrar un denominador común en la ubicación de los sepulcros pero parece apreciarse una manifiesta predilección por altozanos de amplia visibilidad relacionados con accesos naturales entre valles.

Una de las características más definitorias de la arquitectura de los monumentos del grupo es su marcado polimorfismo frente a otros núcleos cercanos como el de Rioja Alavesa-Sonsierra, donde la tónica habitual es la reiteración de los tipos 'de

(1) López de Calle, C. 1993: Los sepulcros megalíticos de Cameros (La Rioja). Tesis Doctoral inédita. Universidad de Zaragoza. Zaragoza. El propio autor nos la facilitó amablemente.

(2) Fernández-Crespo, T. 2012: Antropología y prácticas funerarias en las poblaciones neoliticas finales y calcoliticas de la región natural de La Rioja. Tesis Doctoral inédita. Universidad del País Vasco. Vitoria.

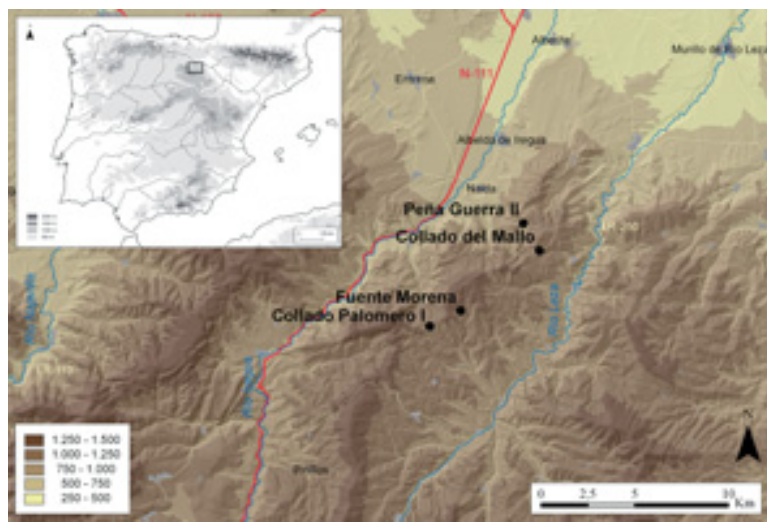

Fig. 1. Localización de la estación megalítica de Cameros (La Rioja) con la ubicación precisa de los monumentos analizados en el trabajo (UTM, ETRS89, 30 T): Peña Guerra II $(X=544.650, Y=4.685 .400)$, Collado del Mallo $(X=545.500$, $\mathrm{Y}=4.683 .950)$, Fuente Morena $(\mathrm{X}=541.350, \mathrm{Y}=4.680 .700)$ y Collado Palomero I ( $\mathrm{X}=539.650, \mathrm{Y}=4.679 .900)$. Fuentes cartográficas: hojas digitales 203, 204, 241 y 242 del MTN25 vectorial (eds. 2003-2008) y MDT25 (ed. 2010) del Instituto Geográfico Nacional de España.

corredor'. En Cameros, junto a soluciones recurrentes como los dólmenes simples (Fuente Morena) o los de corredor (Peña Guerra I y Collado del Mallo), aparecen otras de tipología menos usual como un sepulcro bicameral (Peña Guerra II) o un dolmen con atrio (Collado Palomero I), entre otros.

$\mathrm{Su}$ contenido es también diverso. Es difícil establecer un número mínimo de individuos estándar, ya que la horquilla de inhumados puede variar desde la decena escasa hasta casi el medio centenar. Lo mismo ocurre con el ajuar. La ocupación de los sepulcros durante siglos y la consiguiente introducción de ofrendas permite distinguir fases de uso (neolíticas finales, calcolíticas precampaniformes) que no tienen por qué ser semejantes en todos los casos, como veremos (López de Calle y Tudanca 2005).

\section{APROXIMACIÓN METODOLÓGICA}

Todo el protocolo metodológico, desde las técnicas antropológicas convencionales (FernándezCrespo y de la Rúa 2015) hasta las propias de la Anthropologie de terrain (Duday et al. 1990), se ha orientado y adaptado minuciosamente a la comprensión del funcionamiento de las sepultu- 
ras, desde su construcción hasta su clausura o abandono. El estudio de las osamentas no es por tanto un fin en sí mismo, pero sí constituye una fuente esencial de información.

El inventario exhaustivo de todos los restos esqueléticos ha constituido el pilar fundamental del trabajo (Chambon 2003). La base de datos creada al efecto sigue las pautas establecidas por J. Buikstra y D. H. Ubelaker (1994), recogiendo la identificación y descripción pormenorizada de cada pieza según diferentes criterios (porción, lateralidad, caracteres métricos y no métricos, signos patológicos, alteraciones tafonómicas, etc.). Igualmente $\mathrm{y}$, siempre que ha sido posible, se ha incluido la estimación de la edad y el sexo de los restos (Fernández-Crespo y de la Rúa 2015).

Este sistema de registro ha facilitado, entre otras cosas, el cálculo del número mínimo de individuos (NMI) (White y Folkens 2005: 339) y la observación de los desequilibrios en la representación de una u otra parte anatómica mediante la elaboración de un perfil osteológico plasmado en histogramas estandarizados. Se han seleccionado once piezas para ofrecer una visión sintética de su representatividad: cráneo, mandíbula, escápula, húmero, cúbito, coxal, fémur, rótula, tibia, calcáneo y astrágalo. Éstas forman parte de las principales articulaciones del cuerpo y nada hace sospechar en principio que puedan verse afectadas por una recogida diferencial durante los trabajos de campo, como podría ocurrir con piezas menores (vértebras, costillas, huesos de manos y pies). Dada la habitual fragmentación de los restos, se ha contabilizado la porción mejor representada de cada pieza para ambas lateralidades.

Además se han registrado las huellas que los procesos tafonómicos han dejado en los restos (Behrensmeyer 1978; Botella et al. 2000; Stodder 2008). Las alteraciones en la superficie cortical del hueso producidas por fenómenos físico-químicos de la meteorización (fisuras, grietas, erosiones, descamaciones o exfoliaciones), por la acción de raíces y/o pequeños roedores y carroñeros (improntas vegetales, marcas de dientes) o por el contacto con el fuego, materias colorantes $\mathrm{u}$ hongos, han sido documentadas a través de un minucioso examen macroscópico. Igualmente, el registro de fracturas óseas ha sido una constante. No en vano, la alta fragmentación, en general post-mortem, es parte inherente de la naturaleza de los restos estudiados.

El movimiento de los huesos respecto a su posición original es extremadamente difícil de reconstituir dado que el propio carácter colectivo y acumulativo de los sepulcros ofrece una impresión general de desorden y dispersión de los huesos. No obstante, la localización en el laboratorio de remontajes y de conjuntos de huesos que por sus características (edad, complexión, concordancia articular, patologías) pudieran pertenecer a un mismo individuo (lo que se ha denominado liaisons de deuxième ordre) ha resultado clave para identificar conexiones laxas que durante el trabajo de campo pudieron pasarse por alto.

El examen de la documentación gráfica y escrita generada por los excavadores también ha sido esencial en la discusión de la formación de los contextos. Ha sido de especial interés la observación de conexiones articulares (liaisons de premier ordre), sobre todo las de tipo lábil (cervical, torácica, temporo-mandibular, escápulo-clavicularesternal, costo-esternal, carpo-falángica, rotuliana o metatarso-falángica), que se mantienen durante un tiempo muy corto tras la defunción (Canci y Minnozzi 2005: 73). Su presencia basta para definir el carácter primario de una inhumación, si bien no es posible excluir por completo la existencia de inhumaciones secundarias en un conjunto mayoritario de huesos dislocados (Crubézy et al. 1990: 43). Su ausencia, por el contrario, no comporta necesariamente la asimilación del depósito con una inhumación secundaria. Esta circunstancia puede deberse, por ejemplo, a distintas labores de remoción y ordenación del espacio interno. La aparición de articulaciones persistentes (atlantooccipital, húmero-cubital, lumbar, lumbo-sacra, tibio-femoral, astrágalo-tibial o tarsal) tampoco debe interpretarse como indicador distintivo de una deposición primaria, dado que éstas pueden durar meses o incluso años y soportar articuladas los traslados propios de depósitos en plusieurs temps (Bocquentin 2003: 62).

Mucho más difícil resulta asegurar la existencia de un depósito secundario basándose en argumentos 'negativos' como el carácter incompleto de los esqueletos (en particular cuando escasean las piezas de pequeño tamaño), la selección diferencial de piezas 'nobles' (como cráneos y huesos largos) o un aparente desorden en la disposición de los restos (Bellido y Ascensión 1996: 146). Además, rara vez la fortuna permite identificar manipulaciones (p. ej. marcas propias de la descarnación activa de los cadáveres) que afiancen la posibilidad de un enterramiento secundario (Botella et al. 2000).

Trab. Prehist., 72, N. ${ }^{\circ}$ 2, julio-diciembre 2015, pp. 218-237, ISSN: 0082-5638

doi: $10.3989 /$ tp. 2015.12152 


\section{LAS TUMBAS CAMERANAS}

\subsection{Peña Guerra II (Nalda, La Rioja)}

\subsubsection{Presentación del sitio}

C. L. Pérez Arrondo, J. M. Rodanés y C. López de Calle descubrieron el dolmen de Peña Guerra II en 1979. Ese mismo año se excavó la cámara principal y en 1980 parte del túmulo, delimitándose en su transcurso un recinto valorado como corredor o, más certeramente, como cámara secundaria.

En la cámara principal, de unos $4 \mathrm{~m}^{2}$, se identificaron dos episodios funerarios, separados por un suelo de piedras y con un largo hiato cronológico

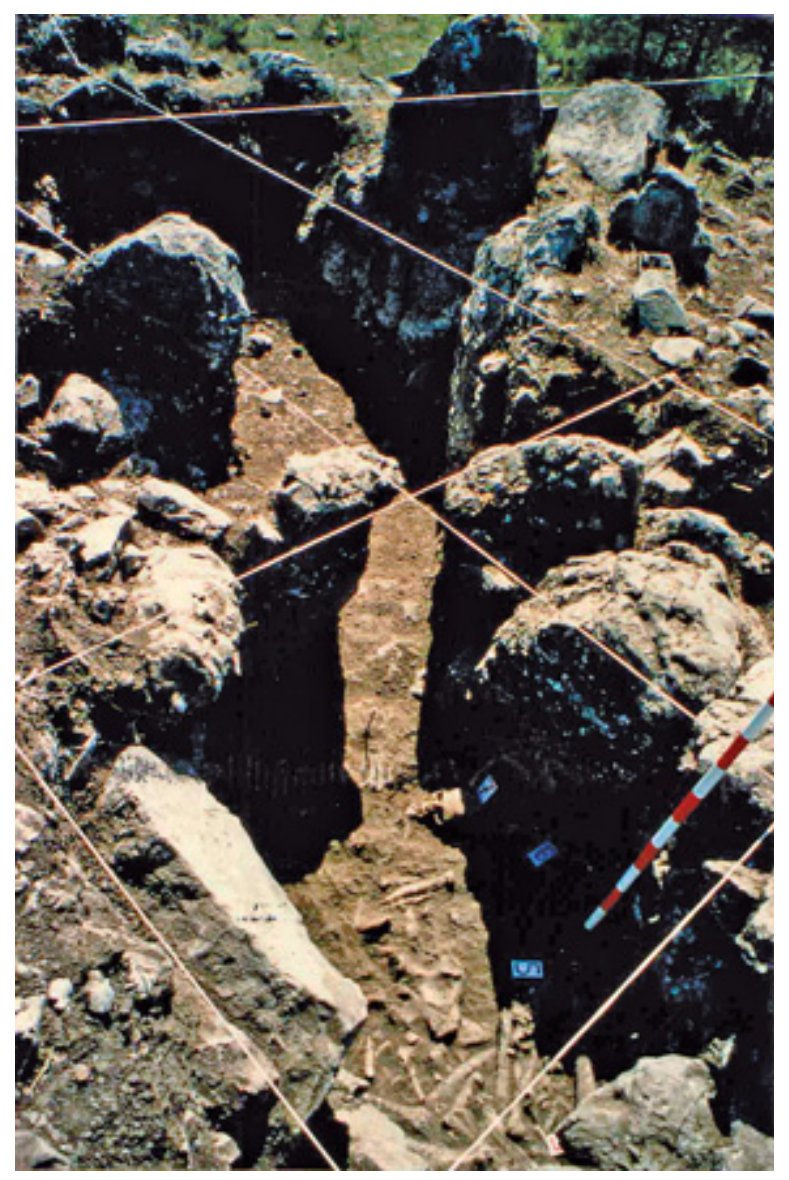

Fig. 2. Peña Guerra II (Nalda, La Rioja) visto desde el Este. En primer plano se observa la cámara secundaria con restos humanos en superficie, pudiéndose apreciar varias conexiones anatómicas y cráneos, señalados con números (foto C. López de Calle 12-VIII-1980). entre ambos. Al nivel I o inferior de cronología neolítica final corresponden los estratos a2 y a3, con fechas sobre hueso humano de $4630 \pm 90 \mathrm{BP}$ (3635-3099 cal. BC, 2 $\sigma$; CSIC-626A) y $4640 \pm$

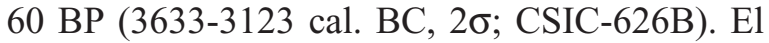
nivel II o superior, asimilado al estrato a1 y asociado a inhumaciones campaniformes, está datado sobre hueso humano en torno al $3410 \pm 60 \mathrm{BP}$

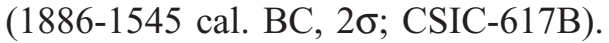

La cámara secundaria de $1 \mathrm{~m}^{2} \mathrm{y}$ en posición excéntrica al túmulo (Fig. 2) puede atribuirse a un momento exclusivamente Neolítico final, denominado nivel 1 (estratos ' $a$ ' a 'e') y fechado en $4750 \pm 30$ BP (3637-3382 cal. BC, 2б; CSIC-969) sobre hueso humano.

\subsubsection{Análisis del depósito}

La cámara principal de Peña Guerra II parece responder a un enterramiento eminentemente primario múltiple acumulativo en dos fases cuyas señas de identidad son la casi total desarticulación y la alta fragmentación. Así, en el nivel neolítico final se contabilizaron 695 esquirlas y 1374 restos identificables, de los que 154 son huesos cortos enteros, 1086 fragmentos de hueso y 134 piezas dentarias. En el nivel calcolítico campaniforme se registraron 585 esquirlas y 242 restos identificables, de los que 18 son huesos enteros, 196 fragmentos de hueso y 28 piezas dentarias aisladas. Entre las alteraciones tafonómicas destacan descamaciones debidas a la meteorización y muy numerosas fracturas postmortem antiguas y recientes. Estas últimas, concentradas especialmente en los cráneos, son más habituales en el nivel superior. No se observan por el contrario marcas compatibles con la actividad de roedores u otros pequeños carnívoros.

Estas evidencias pueden en general vincularse con una activa frecuentación y gestión del espacio sepulcral en el nivel inferior. En el superior, en cambio, podrían deberse también a ciertas remociones clandestinas, en buena parte responsables de su aspecto actual.

Abundando en su carácter posiblemente primario, no es baladí mencionar las conexiones documentadas en el proceso de excavación (3).

(3) Véase n. 1, p. 248.

Trab. Prehist., 72, N. ${ }^{\circ} 2$, julio-diciembre 2015, pp. 218-237, ISSN: 0082-5638 doi: $10.3989 /$ tp.2015.12152 
El nivel inferior ofreció varias relaciones lábiles costales y vertebrales, una agrupación bastante completa de extremidades inferiores y una conexión húmero-cubital, además de algunos casos de patente proximidad e incluso articulación de cráneos y mandíbulas. El nivel superior también aportó un bloque costal-raquídeo en posición parcialmente laxa. A su vez es importante hacer referencia a su perfil osteológico. La representación del nivel neolítico no es óptima, dada la elevada fragmentación de los huesos, pero sí puede considerarse bastante equilibrado (Fig. 4). Además, el gran número de piezas pequeñas (vértebras, huesos de manos y pies) y la presencia de conexiones anatómicas de naturaleza endeble parecen avalar un depósito eminentemente primario. No obstante, el perfil ligeramente irregular no permite descartar puntuales desalojos o limpiezas. El nivel campaniforme, por su parte, ofreció pocos restos y mal conservados, por lo que el perfil osteológico no parece muy representativo.

La utilización funeraria de la cámara principal parece que fue relativamente profusa durante el Neolítico final cuando, al menos, 12 individuos fueron sepultados (3 subadultos y 9 adultos: 5 masculinos, 3 femeninos, 1 indeterminado). Tras un periodo de 'abandono', fue puntualmente reutilizada durante el Calcolítico campaniforme para inhumar sólo a 3 sujetos (1 subadulto y 2 adultos: 1 femenino, 1 indeterminado) (Tab. 1).

La muestra de la cámara secundaria se encontraba también desarticulada y notablemente fragmentada. Se localizaron un total de 857 es-

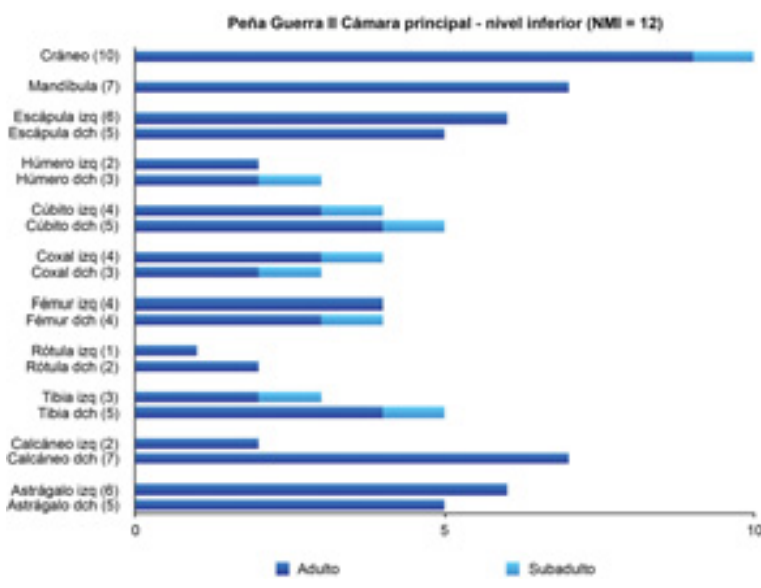

Fig. 3. Perfil osteológico del nivel inferior (Neolítico) de la cámara principal de Peña Guerra II. NMI: Número mínimo de individuos; izq izquierdo, dch derecho.

quirlas y 2502 restos identificables, de los que 211 eran huesos enteros (la práctica totalidad huesos cortos), 2230 fragmentos de hueso y 61 piezas dentarias. En ella destacan las múltiples fracturas antiguas post-mortem pese a la alta consistencia de las piezas a nivel cortical, si bien los huesos largos presentan gran pérdida de tejido esponjoso. Algunos restos estaban teñidos de ocre, el cual ha podido ser definido físico-químicamente como goethita (un óxido de hierro) mediante Espectroscopía Raman.

En este caso, según C. López de Calle y J. A. Ilarraza (1997: 314), el enterramiento podría corresponderse con un posible depósito secundario y simultáneo (Neolítico final) de un mínimo

\begin{tabular}{|c|c|c|c|c|c|c|c|c|}
\hline \multicolumn{9}{|c|}{ Peña Guerra II } \\
\hline \multirow{2}{*}{\multicolumn{2}{|c|}{ Contexto/nivel }} & \multicolumn{6}{|c|}{ Grupos de edad } & \multirow{3}{*}{$\begin{array}{c}\text { Total } \\
12\end{array}$} \\
\hline & & $\begin{array}{c}\text { Infantil I } \\
(0-6)\end{array}$ & $\begin{array}{c}\text { Infantil II } \\
\quad(7-12)\end{array}$ & $\begin{array}{l}\text { Juvenil } \\
(13-19)\end{array}$ & $\begin{array}{c}\text { Adulto } \\
\text { joven } \\
(20-39) \\
\end{array}$ & $\begin{array}{c}\text { Adulto } \\
\text { maduro } \\
(40-59)\end{array}$ & $\begin{array}{c}\text { Adulto } \\
\text { senil } \\
(>60)\end{array}$ & \\
\hline \multirow{2}{*}{$\begin{array}{l}\text { Cámara } \\
\text { principal }\end{array}$} & $\begin{array}{c}\text { Nivel } \\
\text { inferior }\end{array}$ & 1 & 1 & 1 & 4 & 4 & 1 & \\
\hline & $\begin{array}{c}\text { Nivel } \\
\text { superior }\end{array}$ & 0 & 1 & 0 & 2 & 0 & 0 & 3 \\
\hline \multicolumn{2}{|c|}{ Cámara secundaria } & 4 & 4 & 2 & 8 & 8 & 0 & 26 \\
\hline \multicolumn{2}{|c|}{ Total } & 5 & 6 & 3 & 14 & 12 & 1 & 41 \\
\hline
\end{tabular}

Tab. 1. Distribución del número mínimo de individuos de Peña Guerra II (Nalda, La Rioja) según nivel y grupos de edad.

Trab. Prehist., 72, N.. 2, julio-diciembre 2015, pp. 218-237, ISSN: 0082-5638

doi: $10.3989 /$ tp.2015.12152 
de 26 sujetos (10 subadultos y 16 adultos: 6 masculinos, 7 femeninos, 2 alofisos y 1 indeterminado) (Tab. 1). Los autores establecen dicha hipótesis sobre las siguientes evidencias: a) el tamaño francamente pequeño de la cámara, b) la morfología poco apta para una apertura periódica, c) el agrupamiento de la práctica totalidad de los restos en menos de $40 \mathrm{~cm}$ de potencia estratigráfica sin piedras que los hayan sometido a presión (como ocurre en el recinto central), d) la manifiesta diferencia de sus ajuares con respecto a los de la cámara principal, e) la completa desconexión de los restos salvo ejemplos minoritarios de relación entre maxilares y cráneos (Fig. 4), y f) la clara ordenación diferencial de éstos, ya que buena parte de los cráneos se apilaban en el sector meridional de la cámara, protegidos por losas laterales, mientras que haces de huesos largos aparecían concentrados en la zona occidental.

Dichas evidencias parecen bastar por sí solas para abogar por el carácter secundario de la cámara excéntrica. Sin embargo, la presencia de algunas conexiones lábiles, la citada abundancia de huesos de pequeño tamaño y la correcta representación del perfil osteológico (mejor incluso que la resultante del análisis de la principal) -en nuestra opinión y pese a lo esperado- ofrecen argumentos suficientes para no inclinarse, al menos con tanta certeza, por un depósito de naturaleza secundaria (Fig. 5).

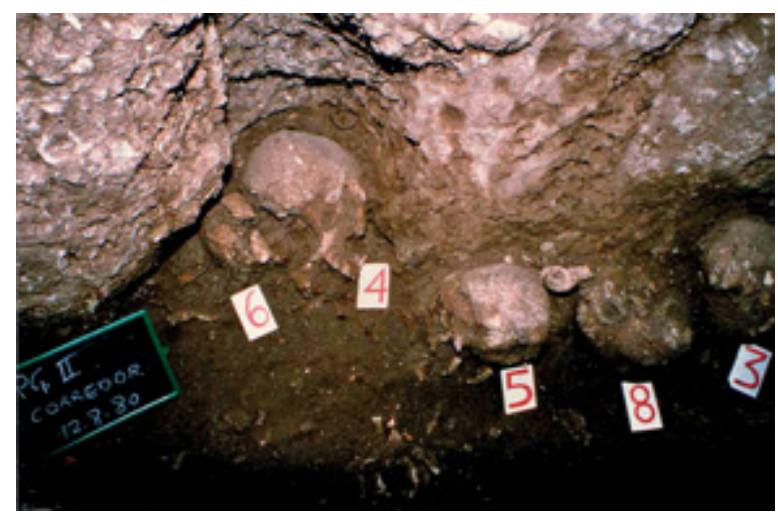

Fig. 4. Cráneos colocados en los intersticios de las losas de la cámara secundaria de Peña Guerra II. Varios conservan la conexión cráneo-mandibular (foto C. López de Calle 12-VIII-1980).

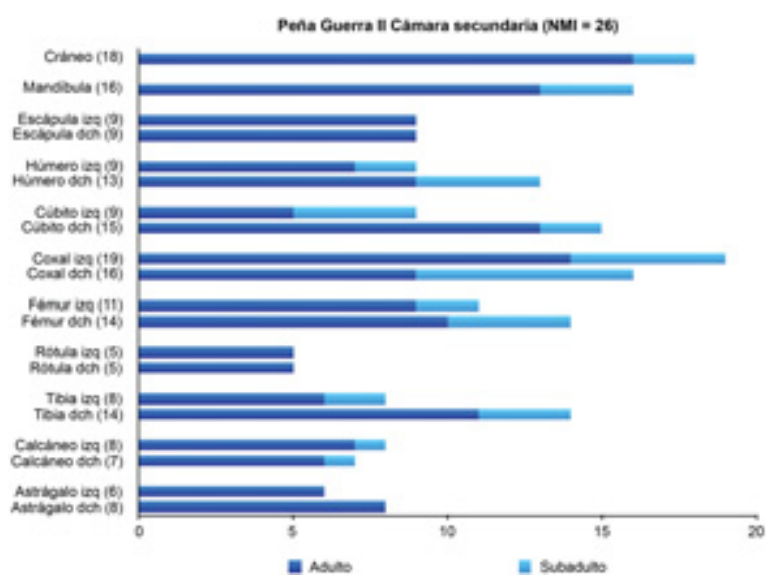

Fig. 5. Perfil osteológico de la cámara secundaria (Neolítico) de Peña Guerra II. NMI: Número mínimo de individuos; izq izquierdo, dch derecho.

\subsubsection{Interpretación de la secuencia de uso}

El rito funerario practicado en la cámara principal del dolmen de Peña Guerra II fue muy posiblemente el de inhumación primaria múltiple acumulativa (al menos en su mayor parte). El material aparece en general inconexo, pero se han localizado conjuntos (algunos de ellos lábiles) en posición anatómica en ambos niveles, el perfil osteológico puede considerarse correcto y se conservan multitud de huesos cortos que muy rara vez se trasladan a depósitos secundarios.

Más complicado es dilucidar las circunstancias del depósito de la cámara secundaria. Como referían C. López de Calle y J. A. Ilarraza (1997: 314), el tamaño, la morfología y la potencia de la cámara parecen poco aptas para una inhumación primaria de tantos cadáveres. Por otro lado la completa desconexión y la cuidada ordenación espacial de algunos restos no tienen por qué relacionarse necesariamente con un depósito secundario, pudiendo vincularse también con ceremonias o labores de aprovechamiento espacial. Del mismo modo, la diferencia en la composición de los ajuares de ambos espacios sepulcrales puede responder sencillamente a razones fortuitas en vista de lo poco abundante de los conjuntos y la indefinición del package funerario prototípico del Neolítico final (si es que existió algo así).

Sin un paralelo claro en el entorno, a partir de los comentarios de J. Clottes (1977) sobre las ar- 
quitecturas dobles de Quercy (Francia), C. López de Calle y J. A. Ilarraza (1997: 314) proponen tres hipótesis para explicar la presencia de la cámara excéntrica: "un traslado corto desde la cámara principal (...) con vistas a obtener espacio suficiente para nuevos enterramientos, el traslado de restos desde otro lugar cuando ya se está usando la cámara principal y, por lo tanto, el apaño de una solución arquitectónica improvisada ante una necesidad imprevista en el diseño original de la sepultura, la ubicación de restos humanos procedentes de una estructura anterior en un mismo espacio tumular pero dentro de un recinto de subrayada individualidad, suficiente para contener huesos pero inapropiado para un uso continuado".

Los tres supuestos presentan el relleno de dicha cámara como un acontecimiento único (con lo que se niega un discurrir cronológico paralelo al uso de la cámara central) fruto de la convergencia de tres circunstancias: adaptación funcional, remodelación arquitectónica y clausura de un área de depósito. Pese a que los tres razonamientos esbozados son perfectamente posibles, los autores admiten que el tercero les parece el más sugerente. Sin embargo, desde un punto de vista antropológico esta última hipótesis es objetable, primero, porque la presencia de gran cantidad de huesos pequeños es muy poco habitual en depósitos en plusieurs temps. En segundo lugar, la 'adecuada' representación de todas las porciones anatómicas (con solo un ligero predominio de cráneos y de huesos largos) sería también excepcional de tratarse de un enterramiento secundario. En tercer lugar, existen algunos ejemplos de relación cráneo-mandibular, una conexión en principio muy significativa a nivel tafonómico por ser de tipo lábil. Sin embargo, según C. López de Calle, dicha relación no sería demasiado significativa porque se trata de la articulación más fácil de reconocer y su correspondencia podría repararse ocasionalmente en el acto de un reordenamiento (4). Estamos de acuerdo en que los restos se beneficiaron de un complejo trabajo de reacomodación en este reducido recinto y en que tal vez las bóvedas craneales fueran depositarias de un cuidado especial. Sin embargo, es imposible imaginar la correcta recomposición de las relaciones cráneo-mandibulares a no ser que pensemos en un traslado de

(4) Véase n. 1, p. 258. los huesos realmente meticuloso y espacialmente corto, quizá desde la cámara principal.

La presencia de huesos pequeños y la esperable representación de todos los segmentos corporales parecen orientarse en el mismo sentido, pues sólo son posibles si abogamos por un 'barrido' minucioso desde la cámara principal. De hecho, es casi imposible hallar una recogida tan escrupulosa de restos en depósitos secundarios. Estas tres observaciones invitan a rechazar la hipótesis de un enterramiento secundario comunal, en el sentido estricto del término, y a decantarse si no por un enterramiento primario (poco probable dadas las características del habitáculo excéntrico), sí por una acumulación de huesos fruto de la necesidad de generar más espacio en la cámara principal. Según López de Calle (5), éstos conformarían "un osario (...) producto de una monda de la cámara principal, ahora ya vacía y dispuesta para recibir nuevas inhumaciones". Podríamos englobar la práctica en lo que se ha convenido en denominar labores de acondicionamiento espacial, ya documentadas en yacimientos como el dolmen portugués de Monte Canelas I gracias, entre otros factores, a una cuidada labor de remontaje (Silva 1997: 243-245). Esa labor, en nuestro caso, no ha podido llevarse a cabo con éxito por la alta fragmentación del material y la ausencia de siglado o fichas identificativas en muchas de las piezas. Aún así, esta hipótesis nos parece la más plausible, ya que explicaría lo restringido de las dimensiones del habitáculo excéntrico, el importante NMI acogido, que dobla el del nivel neolítico de la cámara principal, y la aparente mayor antigüedad de los vestigios humanos en vista de las dataciones radiocarbónicas.

\subsection{Collado del Mallo (Soto de Cameros, La Rioja)}

\subsubsection{Presentación del sitio}

Collado del Mallo fue descubierto en 1988. En 1993 un clandestino expolió parte de su cámara, siendo objeto de una campaña de protección y posterior excavación bajo la dirección de C. López de Calle en 1994, 1995 y 1996. Pese a cier-

(5) Véase n. 1, p. 261.

Trab. Prehist., 72, N. ${ }^{\circ}$ 2, julio-diciembre 2015, pp. 218-237, ISSN: 0082-5638

doi: $10.3989 /$ tp.2015.12152 
tas particularidades, el sepulcro se adapta bien al término de sepulcro de corredor (López de Calle et al. 2001: 73-74).

La cámara medía entre 7 y $8 \mathrm{~m}^{2}$ y tenía una hendidura natural de alrededor de $1 \mathrm{~m}$ de profundidad en su sector meridional. Su contenido apareció gravemente alterado (Fig. 6). En cambio, la zona de acceso, compuesta por un corredor de $7 \mathrm{~m}$ de longitud y la zona de unión con los límites exteriores del túmulo, reveló una estratigrafía intacta y una gran complejidad formal (López de Calle 1994: 13). Allí aparecieron un hogar, dos grandes bloques exentos en posición vertical y un conjunto de huesos humanos quemados, entre otras soluciones menos llamativas.

$\mathrm{Su}$ estudio permitió identificar una secuencia de uso funerario plasmada en diversas fases y/o espacios (López de Calle et al. 2001: 74). La primera ocupación del Neolítico avanzado corresponde a la fase pre-constructiva y primer uso sepulcral del monumento (López de Calle 1994: 15) y se reconoce claramente en el nivel

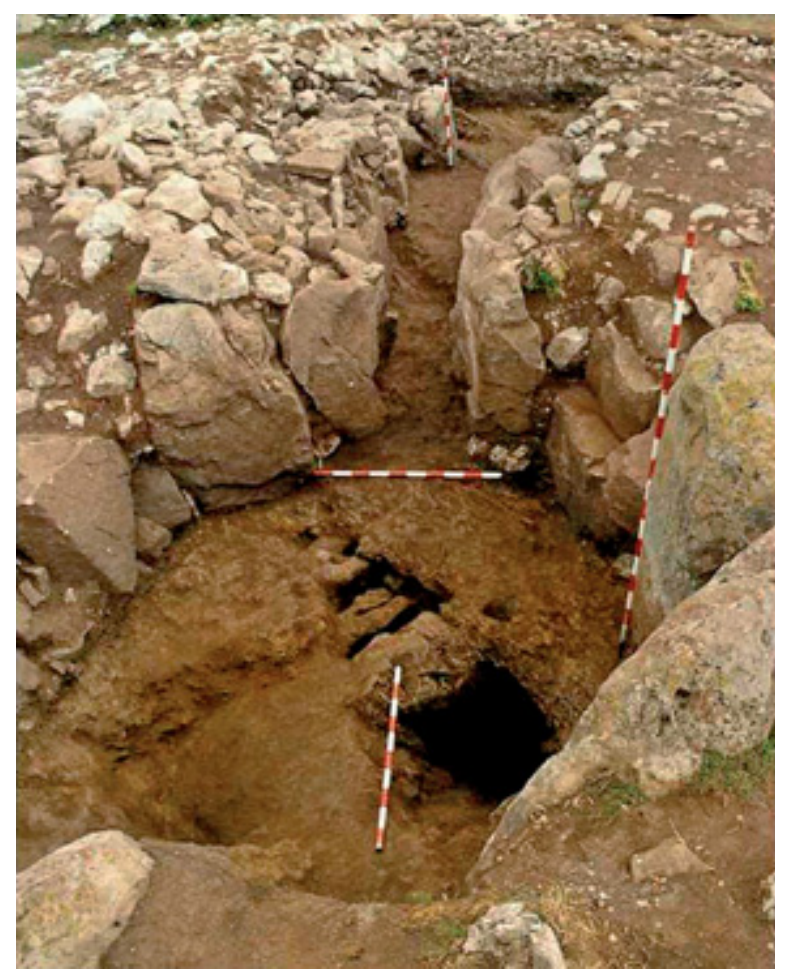

Fig. 6. Dolmen de Collado del Mallo (Soto de Cameros, La Rioja). Vista de la cámara y el corredor (López de Calle y Tudanca 2005: 33). inferior o C del primer tramo del corredor (el que enlaza con la cámara) y bajo un empedrado hallado en el segundo tramo del mismo, con fechas de 4430 \pm 70 BP (3339-2916 cal. BC, $2 \sigma$; Beta-89.987) y 4700 \pm 90 BP (3662-3121 cal. BC, $2 \sigma$; Beta-89.986) respectivamente, y también bajo el cuadrante nororiental del túmulo.

La segunda etapa de uso, atribuida al Calcolítico temprano se identifica en las cotas inferiores de los pocos sectores de la cámara que permanecían inalterados, con dataciones de $3860 \pm 70 \mathrm{BP}$ (2561-2136 cal. BC, $2 \sigma$; Beta-89.988) y $4000 \pm 70$ BP (2858-2297 cal. BC, 2б; Beta-89.989); y en el nivel superior o $\mathrm{B}$ del primer tramo del corredor, con una fecha de 3950 \pm 80 BP (2831-2206 cal. BC, 2 $\sigma$; Beta-89.991).

La tercera y última fase, del Calcolítico reciente se detecta en las cotas superiores del tramo segundo del corredor, a la que corresponden el empedrado y las evidencias de cremación de la zona de acceso, y de la cámara (nivel A), fechada en $3840 \pm 70$ BP (2477-2049 cal. BC, 2 $\sigma$; Beta89.990).

\subsubsection{Análisis del depósito}

La muestra total de Collado del Mallo se compone de 9618 esquirlas y 5122 restos identificables, de los que 695 son huesos enteros, 3452 fragmentos de hueso y 975 piezas dentarias aisladas. Desafortunadamente, la parquedad de la información aportada por las fichas de campo que acompañaban a los restos impidió todo conato de distribución de éstos por niveles en el laboratorio. Las alteraciones más habituales derivan de los efectos de la intemperie, como descamaciones y grietas, y sobre todo del alto número de fracturas antiguas y recientes. Abundan también las improntas de raíces, cuya introducción en las diáfisis de los huesos largos llega a veces a estallarlos. Hay evidencias de infección por organismos saprofitos debido a la deficiente transpiración de las bolsas de plástico en que se conservaban los restos. Finalmente, el registro de un pequeño número de fragmentos quemados corrobora las informaciones obtenidas sobre el terreno.

El depósito parece responder a un enterramiento eminentemente primario, pese a no reconocerse conexiones anatómicas de interés (López de Calle 
2002: 234). Así permiten avalarlo, al menos, los numerosos huesos de pequeño tamaño recuperados. El perfil osteológico no tendría en nuestra opinión demasiado poder diagnóstico, dado el pésimo estado de conservación de toda la colección (Fig. 7).

Coincidimos con C. López de Calle en que "el gran desorden [y, podría añadirse, fragmentación] observado en los restos óseos es producto, por un lado, de una intensa reutilización del sepulcro, con el consiguiente desbaratamiento de las conexiones anatómicas, $y$, por otro, de agrupaciones intencionadas de huesos largos en determinadas zonas" (López de Calle 1994: 14), y no fruto de depósitos secundarios generalizados, como podría sugerir el mencionado hallazgo de restos óseos quemados en la zona de acceso. No en vano, tras la valoración antropológica de tales evidencias, sólo 12 fragmentos (de los cerca de 250 que componían el conjunto recogido en dicha área) se han visto

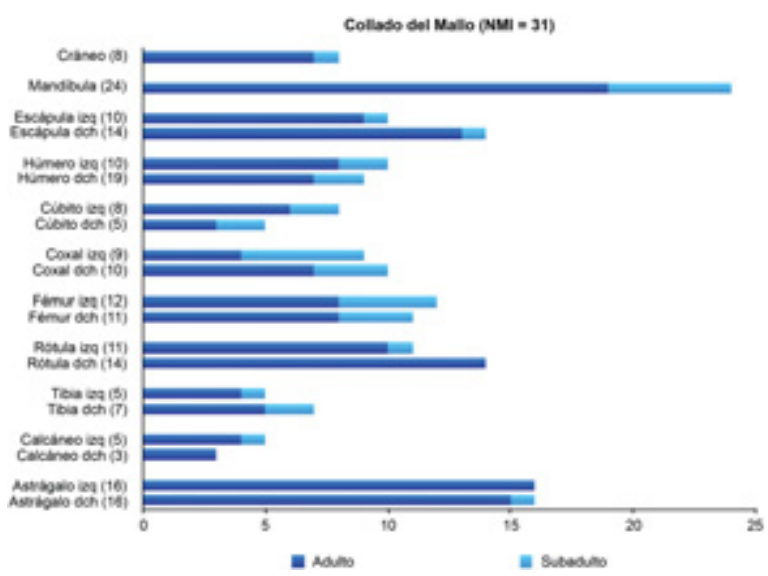

Fig. 7. Perfil osteológico de Collado del Mallo. NMI: Número Mínimo de Individuos; izq izquierdo, dch derecho. realmente afectados por el fuego. Los restantes vestigios de cremación son realmente excepcionales en el yacimiento, reduciéndose a 43 evidencias: un fragmento de bóveda craneal, parte de un maxilar superior, 5 fragmentos dentarios y 36 esquirlas.

El escaso poder diagnóstico de esta docena de esquirlas hace imposible extraer conclusiones sustanciosas respecto al estado de los huesos en el momento de la quema, aunque sí revela una exposición a temperaturas medias de entre $200 \mathrm{y}$ $600{ }^{\circ} \mathrm{C}$ a partir de su coloración marrón-negruzca y poco homogénea (Hummel et al. 1988). Sin embargo y pese a la yuxtaposición de dos acciones relacionadas con el uso del fuego (huesos cremados y un hogar junto a ellos) en el área de acceso, los datos antracológicos excluyen cualquier relación entre ambas circunstancias. El estudio de los macrorrestos vegetales sugiere la clara asociación entre los huesos humanos quemados y carbones de avellano (92\% de la muestra) (López de Calle et al. 2001: 78-79). En cambio, los materiales leñosos recuperados en el hogar corresponden a madera de tejo (López de Calle 2002: 237). Parece plausible, por tanto y en este caso, la correspondencia de estos restos con la introducción puntual de pequeños paquetes secundarios.

Finalmente, la población inhumada incluye un NMI de 31 individuos (12 subadultos y 19 adultos: 10 masculinos, 5 femeninos, 4 indeterminados) en todo el conjunto del depósito, dada la ya comentada imposibilidad de distribuirlos por niveles (Tab. 2).

\subsubsection{Interpretación de la secuencia de uso}

El rito funerario realizado en Collado del Mallo fue muy posiblemente el de inhumación pri-

\begin{tabular}{|c|c|c|c|c|c|c|c|}
\hline \multicolumn{7}{|c|}{ Collado del Mallo } & \\
\hline \multirow{3}{*}{ Contexto/nivel } & \multicolumn{7}{|c|}{ Grupos de edad } \\
\cline { 2 - 7 } & $\begin{array}{c}\text { Infantil I } \\
\mathbf{( 0 - 6 )}\end{array}$ & $\begin{array}{c}\text { Infantil } \\
\text { II } \\
\mathbf{( 7 - 1 2 )}\end{array}$ & $\begin{array}{c}\text { Juvenil } \\
(\mathbf{1 3 - 1 9 )}\end{array}$ & $\begin{array}{c}\text { Adulto } \\
\text { joven } \\
(\mathbf{2 0 - 3 9 )}\end{array}$ & $\begin{array}{c}\text { Adulto } \\
\text { maduro } \\
(\mathbf{4 0 - 5 9 )}\end{array}$ & $\begin{array}{c}\text { Adulto } \\
\text { indet. } \\
(>\mathbf{2 0})\end{array}$ & \multirow{2}{*}{ Total } \\
\hline General & 5 & 5 & 2 & 7 & 5 & 7 & 31 \\
\hline
\end{tabular}

Tab. 2. Distribución del número mínimo de individuos de Collado del Mallo (Soto de Cameros, La Rioja) según los grupos de edad.

Trab. Prehist., 72, N.. 2, julio-diciembre 2015, pp. 218-237, ISSN: 0082-5638

doi: $10.3989 /$ tp.2015.12152 
maria, al menos en su mayor parte, pese a que el material se encontraba inconexo, sin orden anatómico y en ciertas áreas, en apariencia, agrupado intencionalmente. Coincidimos con C. López de Calle (1994: 14) en que es más correcto interpretar esta evidencia como un tratamiento o cuidado funerario -tal vez orientado al intenso aprovechamiento del espacio sepulcral- que como resultado de complejas y masivas prácticas de inhumación secundaria, a falta de otras evidencias que apoyen esta hipótesis, como podrían ser serias anomalías en la representatividad de los huesos pequeños.

Sin embargo, la existencia de una pequeña muestra ósea sometida a la acción del fuego y su casi exclusiva asociación con carbones de avellano invita a pensar, al menos para este conjunto, en un fenómeno no meramente accidental. C. López de Calle (6) propone atribuirla a una acción simultánea sobre los restos de varios individuos, sin descartar una introducción periódica de restos sometidos uno a uno a los efectos del fuego, o incluso, una combinación de ambos gestos. Para nosotros, honestamente, esto resulta imposible de precisar.

Para terminar, el reconocimiento de estratos previos a la construcción de la sepultura (nivel inferior o C) pueden sin muchas dudas ser interpretados como consecuencia de la implantación del sepulcro megalítico sobre un área funeraria anterior. En ellos, "los restos humanos asociados a elementos neolíticos intactos yacen bajo el empedrado del corredor, dentro de los límites de un espacio que podemos juzgar como apropiado o habitual para la deposición fúnebre. Pero el nivel discurre, sin solución de continuidad, bajo el túmulo, al menos en el cuadrante nororiental" (López de Calle e Ilarraza 1997: 316).

\subsection{Fuente Morena (Montalvo de Cameros, La Rioja)}

\subsubsection{Presentación del sitio}

Fuente Morena fue descubierto en julio de 1986 por P. y C. Álvarez Clavijo, J. Ceniceros y M. L. Carrillo, y excavado ese mismo mes en una

(6) Véase n. 1, p. 236. única campaña dirigida por C. L. Pérez Arrondo. El sitio podría definirse como un sepulcro simple. El desplome de la mayor parte de las losas no permitió establecer si contaba con algún sistema de acceso con límites definidos, si bien propició que una buena porción de la zona central de la cámara se preservase inalterada, estando el resto del depósito removido desde antiguo. La zona intacta (estrato 1) ofreció una fecha sobre hueso humano de 4700 $\pm 25 \mathrm{BP}$ (3627-3374 cal. BC, $2 \sigma$; CSIC-968)(7), lo que permite atribuirlo al Neolítico final.

\subsubsection{Análisis del depósito}

La muestra de Fuente Morena comprende un total de 1804 esquirlas y 955 restos identificables, de los que tan sólo 24 son huesos enteros, 779 fragmentos de hueso y 152 piezas dentarias aisladas. Como en otros sepulcros, la muy elevada fragmentación de los restos es la alteración tafonómica más sobresaliente, acompañada de descamaciones e improntas vegetales.

El depósito parece responder a priori a una inhumación primaria en vista de la existencia de un sujeto en conexión anatómica parcial al que "la caída de una losa de la cámara, en un momento no determinado de la historia de sepulcro, había aplastado completamente sin llegar a desbaratar su posición original" (López de Calle 1992: 37), manteniéndose intactas tanto la relación entre brazo y antebrazo como la posición del conjunto vertebral. La distancia a la que aparece el cráneo (aplastado y con la mandíbula conectada) y, sobre todo, la disposición del raquis, permiten estimar una posición replegada.

No obstante, el colectivo inhumado asciende a un mínimo de 8 individuos ( 3 subadultos y 5 adultos, de los que 3 son masculinos, 1 femenino y 1 indeterminado) (Tab. 3) y, pese al hallazgo de dicho sujeto parcialmente conectado, ha de señalarse la inusual escasez de elementos de pequeño tamaño, como huesos de pies y manos, piezas vertebrales o fragmentos costales, y la sobrerrepresentación de cráneos y huesos largos (Fig. 8).

(7) Véase n. 1, p. 133.

Trab. Prehist., 72, N. ${ }^{\circ}$ 2, julio-diciembre 2015, pp. 218-237, ISSN: 0082-5638 doi: $10.3989 /$ tp.2015.12152 


\begin{tabular}{|c|c|c|c|c|c|c|c|}
\hline \multicolumn{7}{|c|}{ Grupos de edad } & \\
\hline \multirow{3}{*}{ Contexto/Nivel } & \multicolumn{7}{|c|}{ Monte Morena } \\
\cline { 2 - 7 } & $\begin{array}{c}\text { Infantil I } \\
\mathbf{( 0 - 6 )}\end{array}$ & $\begin{array}{c}\text { Infantil } \\
\text { II } \\
\mathbf{( 7 - 1 2 )}\end{array}$ & $\begin{array}{c}\text { Juvenil } \\
(\mathbf{1 3 - 1 9 )}\end{array}$ & $\begin{array}{c}\text { Adulto } \\
\text { joven } \\
(\mathbf{2 0 - 3 9 )}\end{array}$ & $\begin{array}{c}\text { Adulto } \\
\text { maduro } \\
(\mathbf{4 0 - 5 9 )}\end{array}$ & $\begin{array}{c}\text { Adulto } \\
\text { indet. } \\
(>20)\end{array}$ & \multirow{2}{*}{ Total } \\
\hline General & 0 & 1 & 2 & 4 & 0 & 1 & 8 \\
\hline
\end{tabular}

Tab. 3. Distribución del número mínimo de individuos de Fuente Morena (Montalvo de Cameros, La Rioja) según los grupos de edad.

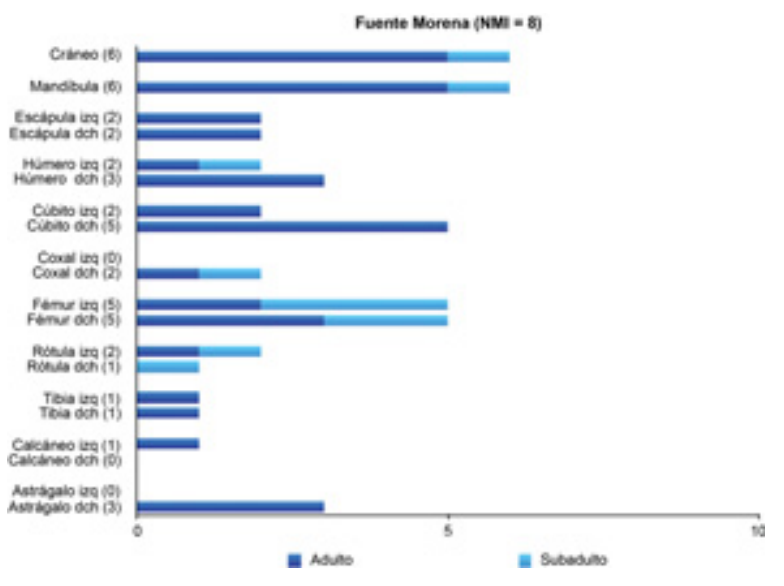

Fig. 8. Perfil osteológico de Fuente Morena (Montalvo de Cameros, La Rioja). NMI: Número mínimo de individuos; izq izquierdo, dch derecho.

\subsubsection{Interpretación de la secuencia de uso}

El rito funerario practicado en Fuente Morena bien pudo ser el de inhumación primaria, al menos en parte, como evidencia el sujeto en conexión parcial. Sin embargo, la abrumadora escasez de huesos cortos y elementos costo-vertebrales (y la profanación de parte de la cámara) nos deja en duda sobre la naturaleza total del sepulcro. Esta circunstancia podría deberse a labores habituales de gestión del espacio sepulcral, como las limpiezas selectivas. A este respecto, resulta significativa la observación durante los trabajos de campo de restos de materias colorantes rojizas de naturaleza indeterminada en algunos sectores del fondo de la cámara (8), que bien pudieran tener una función

(8) Véase n. 1, p. 233. profiláctica vinculada con dichas prácticas, pese a no haber llegado a teñir los restos humanos.

Tampoco conviene descartar la posibilidad de un enterramiento secundario. La escasa colmatación documentada en el monumento (tan sólo un mínimo de 8 individuos) no parece requerir ese tipo de prácticas, en principio motivadas por la necesidad de liberar espacio.

\subsection{Collado Palomero I (Viguera, La Rioja)}

\subsubsection{Presentación del sitio}

El dolmen de Collado Palomero I, descubierto en 1981 por D. Ortega Fernández, fue objeto de cuatro campañas de excavación, dirigidas por C. Pérez Arrondo en 1982, 1985, 1986 y por C. López de Calle en 1987, concluyéndose que parece adaptarse a la tipología de sepulcro simple con atrio ante la entrada (Pérez Arrondo y López de Calle 1988).

La cámara, de entre 7 y $8 \mathrm{~m}^{2}$, estaba totalmente profanada, ofreciendo restos humanos mínimos, dispersos y muy fragmentados. Por su parte, la supuesta zona de acceso o atrio se halló intacta. La línea de unión entre esta zona y la cámara podría parecer dudosa en un principio, por existir una piedra de cierre entre ambas (Fig. 9). Sin embargo, su menor alzado respecto a las losas camerales y la existencia de lajas que parecen arropar el camino hacen pensar en su concepción como medio de ingreso a la cámara.

Los datos obtenidos en la excavación de esta área han permitido proponer la existencia de tres niveles (Pérez Arrondo y López de Calle 1988: 38-40). El Nivel B1 (subyacente al conjunto fune-

Trab. Prehist., 72, N. ${ }^{\circ}$ 2, julio-diciembre 2015, pp. 218-237, ISSN: 0082-5638

doi: $10.3989 /$ tp. 2015.12152 


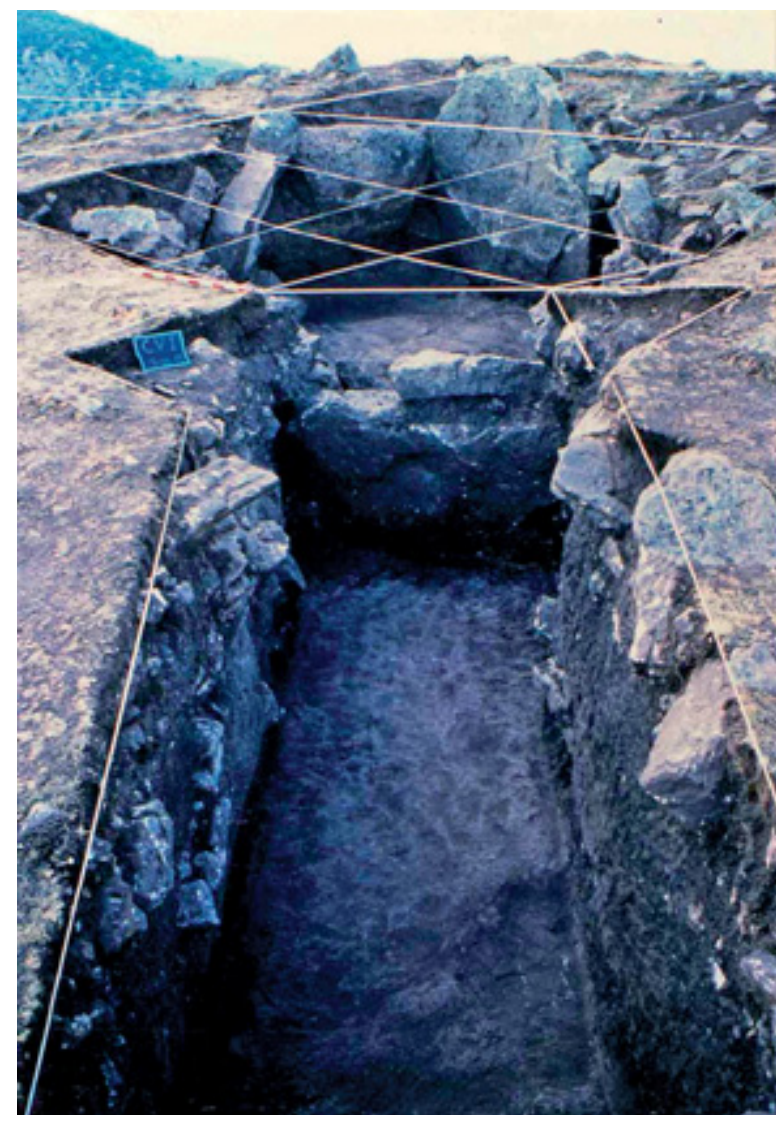

Fig. 9. Collado Palomero I (Viguera, La Rioja). La piedra de cierre vista desde el corte del falso corredor. Las dos piezas que aparecen casi al fondo y cercanas a dicha piedra corresponden a la estructura elíptica descubierta en 1986, la cual contenía restos de un hipotético enterramiento secundario (foto C. López de Calle 9-VII-1986).

rario) tiene 5 estructuras artificiales: a) una alineación elíptica de piedras (Fig. 10A) que encerraba escasos vestigios; b) tres hogares, asociados a restos humanos, ajuares y fragmentos óseos animales de cronología neolítica, datados en $4730 \pm 30 \mathrm{BP}$ (3635-3377 cal. BC, 2б; CSIC-952) gracias a una muestra de carbón (Fig. 10B) y c) un pequeño hoyo relleno de piedras, algunas de ellas con rastros de fuego.

El Nivel B2, Calcolítico precampaniforme, presenta restos humanos escasos e inconexos, unos teñidos de ocre amarillo y otros con señales de fuego. El conjunto fue fechado en $4270 \pm 60 \mathrm{BP}$ (3084-2669 cal. BC, 20; CSIC-1065) a partir de hueso humano.
El Nivel A1 acoge diversos sujetos en la parte más alta, uno de ellos fechado en $3680 \pm 20 \mathrm{BP}$

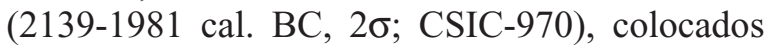
bajo lajas planas de buen tamaño sobre las que se disponía un interesante ajuar campaniforme.

\subsubsection{Análisis del depósito}

La muestra del atrio de Collado Palomero I, recordemos el total expolio de la cámara, se compone en el nivel B1 de 719 esquirlas y 43 restos identificables que incluyen 3 huesos enteros, 36 fragmentos óseos y 4 fragmentos de diente. El nivel B2 tiene 359 esquirlas y 213 huesos identificables, de los que 20 son huesos enteros, 145 fragmentos y 48 piezas dentarias aisladas. El nivel A1 comprende 937 esquirlas y 689 restos identificables, de los que 15 son huesos completos, 607 fragmentos de hueso y 67 piezas dentarias aisladas. En cuanto a los procesos tafonómicos, destacan las múltiples fracturas antiguas postmortem y la notoria alteración en la superficie cortical de los huesos por efectos de la intemperie y por la acción de raíces y pequeños roedores. También aparecieron algunos restos con señales de fuego en todos los niveles. En cambio, no se halló ninguna evidencia de coloración ocre en los huesos del nivel B2, impidiendo certificar las informaciones recogidas en los trabajos de campo.

Los depósitos no parecen responder a un enterramiento eminentemente primario, pese a haberse reconocido posibles conexiones anatómicas en los niveles calcolíticos durante la excavación. Así parece avalarlo, al menos en el nivel A1, el predominio de piezas nobles y el anómalo perfil osteológico (Fig. 11), no siendo posible valorarlo en los niveles B2 y B1 debido a la exigüidad de los conjuntos. Sin embargo, recordemos que apenas se dispone de datos sobre el contenido de la cámara, lugar donde verdaderamente habría que valorar la naturaleza del monumento. Son de gran interés a este respecto los fragmentos óseos con huellas innegables de acción ígnea procedentes de $\mathrm{B} 2$ y A1, mientras en B1 la afectación es muy dudosa pues la muestra se limita a un diente y cuatro esquirlas. Las pequeñas dimensiones de dichos fragmentos, de aspecto generalmente negruzco o ahumado (una coloración propia de 

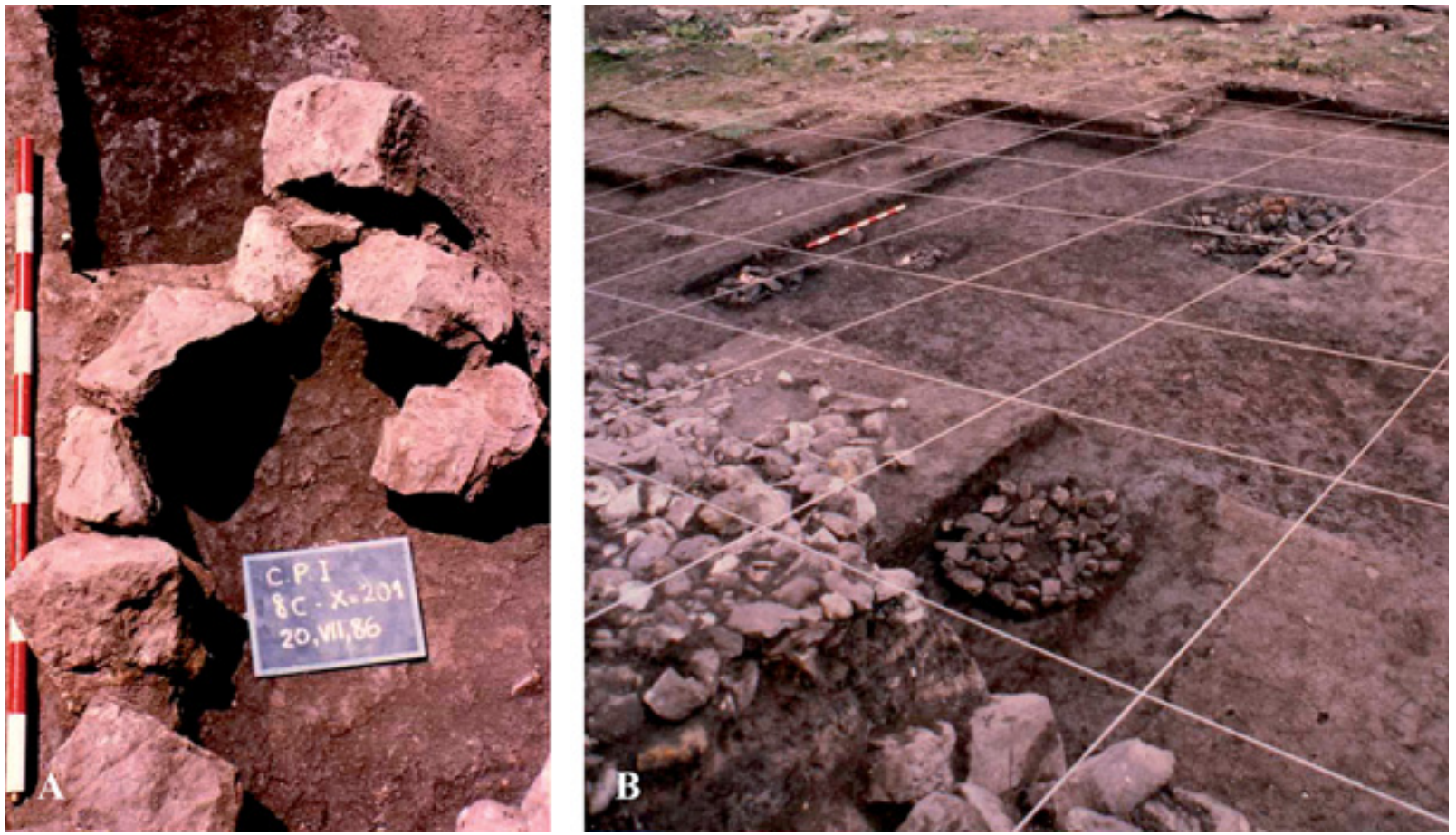

Fig. 10. Collado Palomero I: nivel B1. A) Apariencia de la estructura elíptica de piedras tras su excavación (López de Calle 1992: 39), B) Disposición general de los hogares (foto C. López de Calle 30-VII-1987).

una combustión entre los 200 y los $600{ }^{\circ} \mathrm{C}$ ), no permiten distinguir el estado del hueso (fresco o seco) en el momento de la quema.

Dichas evidencias se refieren a elementos craneales y huesos largos de forma abrumadora, siendo notable la escasez de costillas, vértebras y otros huesos pequeños localizados en el sepulcro (sobre todo en A1). Por ello no es nada improbable que la cremación se hubiera efectuado sobre restos procedentes de una selección previa, siendo en tal caso plausible su llegada al sepulcro en 'seco', esto es, ya descarnados.

De la población inhumada (Tab. 4) en el nivel B1 (Neolítico final) tan sólo pudo estimarse con seguridad la presencia de un sujeto adulto femenino, a partir de las piezas localizadas en la supuesta estructura individualizante. El resto del nivel, compuesto básicamente por esquirlas, no

\begin{tabular}{|c|c|c|c|c|c|c|c|c|}
\hline \multicolumn{9}{|c|}{ Collado Palomero I } \\
\hline \multirow{2}{*}{\multicolumn{2}{|c|}{ Contexto/Nivel }} & \multicolumn{6}{|c|}{ Grupos de edad } & \multirow[b]{2}{*}{ Total } \\
\hline & & $\begin{array}{c}\text { Infantil I } \\
(0-6)\end{array}$ & $\begin{array}{c}\text { Infantil } \\
\text { II } \\
(7-12)\end{array}$ & $\begin{array}{l}\text { Juvenil } \\
(13-19)\end{array}$ & $\begin{array}{c}\text { Adulto } \\
\text { joven } \\
(20-39)\end{array}$ & $\begin{array}{c}\text { Adulto } \\
\text { maduro } \\
(40-59)\end{array}$ & $\begin{array}{c}\text { Adulto } \\
\text { senil } \\
(>60) \\
\end{array}$ & \\
\hline \multirow{3}{*}{ Atrio } & Nivel A1 & 1 & 1 & 1 & 0 & 0 & 6 & 9 \\
\hline & Nivel B2 & 0 & 1 & 0 & 1 & 0 & 0 & 2 \\
\hline & Nivel B1 & 0 & 0 & 0 & 0 & 0 & 1 & 1 \\
\hline \multicolumn{2}{|c|}{ TOTAL } & 1 & 2 & 1 & 1 & 0 & 7 & 12 \\
\hline
\end{tabular}

Tab. 4. Distribución del número mínimo de individuos de Collado Palomero I (Viguera, La Rioja) según nivel y grupos de edad. 


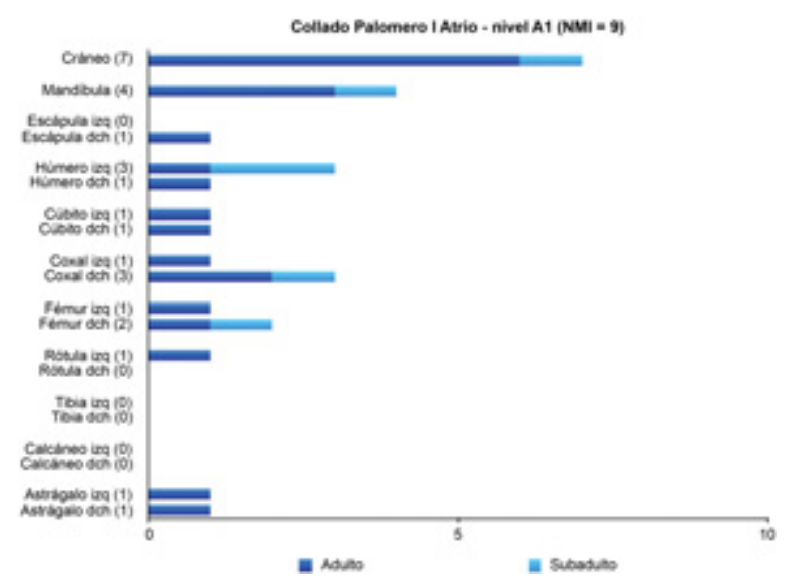

Fig. 11. Perfil osteológico del nivel A1 (Calcolítico campaniforme) del atrio de Collado Palomero I. NMI: Número mínimo de individuos; izq izquierdo, dch derecho.

permite definir con seguridad otros individuos. En el nivel B2 (Calcolítico precampaniforme), también con restos humanos muy escasos, se estimó un número mínimo de 2 individuos: un infantil II $\mathrm{y}$ un adulto joven de sexo indeterminado.

En el nivel A1 (Calcolítico campaniforme), pese a la referencia en los trabajos de campo a la localización de cerca de quince calotas craneales (López de Calle 2002: 234), la intensa fragmentación que manifiestan los restos y la ausencia de individualización de cada conjunto craneal en bolsas independientes hacen imposible identificar en el laboratorio un número tan elevado. De hecho, solamente se han podido identificar 6 bóvedas craneales adultas de sexo indeterminado. Junto a esto, debemos señalar: 1 infantil I, 1 infantil II y 1 juvenil. Es decir, un mínimo de 9 sujetos.

\subsubsection{Interpretación de la secuencia de uso}

Es muy posible que el rito realizado en el interior del sepulcro de Collado Palomero I sea el de deposición secundaria, al menos en el nivel A1. Parecen erguirse como argumentos difícilmente cuestionables las serias irregularidades detectadas en la representatividad de las partes anatómicas. Al abrumador predominio de fragmentos de bóveda craneal y porciones, sobre todo mediales, de huesos largos se opone la práctica inexistencia de elementos del esqueleto axial y huesos cortos. La dicotomía se antoja demasiado significativa para pensar en una eliminación intencional de piezas pequeñas durante labores ocasionales de limpieza, en vez de en una, más probable, introducción o acumulación intencional de piezas 'nobles'. Algo más incierto es el caso de B2, dada la carestía y las penurias en la conservación de las piezas halladas, aunque para C. López de Calle es probable que también respondan a este tipo de inhumación (9).

Respecto a los fragmentos óseos con signos inequívocos de haber sido sometidos a la acción del fuego hallados en sendos niveles, no es descartable que fuesen trasladados al propio depósito cuando ya habían perdido los tejidos blandos y previa selección (especialmente en A1), aunque el mal estado de conservación de la muestra no permite corroborar esta hipótesis.

Finalmente no es improbable que la estructura elíptica de piedras hallada en B1 también conforme un enterramiento secundario, en este caso individual. La conjetura es algo arriesgada al no ser las piezas localizadas (una clavícula, un calcáneo, varias falanges y fragmentos de costillas) en absoluto frecuentes en este tipo de depósitos, pero adquiere cierta solidez a tenor de la escasa entidad y representatividad de los vestigios en el resto del nivel. No es imposible que esa construcción haya salvaguardado de manera especial la integridad de tales huesos, de ahí el desigual estado de conservación con el resto del conjunto, pero tampoco lo es que la muestra ósea conservada no responda al total del conjunto inicialmente depositado. A este respecto, es remarcable la aparente coherencia entre el sexo y la edad del sujeto allí inhumado y las piezas de cultura material asociadas a él (un punzón y una piedra volandera de molino). Dicha suerte tiene paralelos en el entorno, como la estructura subcircular del dolmen navarro de Aizibita, que acogía los restos de, al menos, un adulto y un infantil junto a una considerable concentración de elementos líticos y adornos (Beguiristain 2007/08: 709).

M. T. Andrés (1997: 432) sugiere que el contenido del óvalo pétreo, basándose en su anterioridad al sepulcro y en las estructuras de combustión del nivel B1, podría ser producto del 'olvido' de algunos huesos por parte de la comunidad asentada en aquel paraje, cuando abandona el lugar y traslada los restos de sus antepasados. La ex-

(9) Véase n. 1, p. 239.

Trab. Prehist., 72, N. ${ }^{\circ}$ 2, julio-diciembre 2015, pp. 218-237, ISSN: 0082-5638 doi: $10.3989 /$ tp.2015.12152 
plicación tiene ciertos cabos sueltos como "que, sin ser restos muy significativos, desde luego no son invisibles y, sobre todo, que el pequeño óvalo de piedras se asienta sobre el suelo y en una cota ligeramente superior que los hogares (...), de forma que la relación entre vivos y muertos, en la hipótesis de la profesora Andrés, sería la de pura convivencia" (López de Calle 2002: 240). Sin embargo resulta bastante plausible, más aún si pensamos en los testimonios de estratos subtumulares con signos de actividades domésticas en monumentos funerarios de áreas tanto peninsulares como extrapeninsulares (Delibes et al. 1997).

Como hipótesis alternativa para explicar las evidencias localizadas en esta área de acceso, C. López de Calle (2002: 237) planteaba en sus últimos artículos la relación de tales estructuras con una contundente clausura del sepulcro. La idea, sin demasiado eco, quedaría refutada tras la obtención de fechas radiocarbónicas que situaban al nivel B1 como el más antiguo del sepulcro. No obstante, coincidimos con él en que es "la historia arquitectónica del sepulcro y no un hipotético antecedente de habitación lo que explica satisfactoriamente los hogares de Collado Palomero I" (López de Calle 2002: 237).

Proponemos que sea un acto de 'inauguración' o apertura y no de clausura o disfuncionalización, como defendía este autor, lo que explique la presencia de estas estructuras en la zona de la entrada. Esta suposición se vería avalada tanto por la posición estratigráfica de los hogares y su datación absoluta como por la carencia de indicios de estructuras en la apertura de un corte tumular en la zona norte. Tampoco casaría mal con la presencia de restos animales, fragmentos cerámicos y útiles en sílex relacionables, como ya decía C. López de Calle, con la celebración de un supuesto banquete ritual.

El análisis del material lítico confirma que los límites del atrio sirvieron como lugar de talla, "quizá como actividad inherente al consumo alimenticio o a la preparación y descuartizamiento de las piezas consumidas (...) in situ" (López de Ca1le 2002: 240-241). A esta circunstancia (que siendo fieles a la verdad tampoco desentonaría con lo esperado en un hábitat) han de sumarse otras dos. Al parecer, las hogueras fueron "tapadas muy poco después de su último uso, ya que conservaban restos de materiales leñosos carbonizados cuya desintegración al aire libre es bastante rápida". Además los restos cerámicos, "muy fragmentados y, en lo poco que se puede saber, correspondientes todos a recipientes de pequeña talla, permiten imaginar que no se usarían como cacharros de cocina y que su fractura, muy acusada pero sin señales de rodamiento, sería quizá intencional".

Imbricado en todo este escenario estaría el pequeño receptáculo pétreo donde fueron depositados los exiguos restos humanos que el estudio antropológico ha permitido estimar como pertenecientes a una mujer adulta. Siendo éste el único conjunto fúnebre de cierta entidad detectado en B1, ¿por qué no plantear su asimilación con un depósito fundacional? No queremos ocultar, sin embargo, que "bajo el túmulo en sentido estricto (estrato 6, infrayacente), se recogerían también restos de animales y piezas cerámicas de las que lo más llamativo son tres fragmentos de cerámica impresa" (López de Calle 2002: 238-239), un descubrimiento que, en principio, vendría a apoyar la opinión de M. T. Andrés. No obstante, la estrecha relación estilística y artesanal de dichos fragmentos con otros hallados en la cercana Cueva Lóbrega (Torrecilla de Cameros), en un contexto Neolítico antiguo datado en torno a $6220 \pm 100 \mathrm{BP}(5465-4911 \mathrm{cal}$. BC, $2 \sigma$; GrN-16110) (Barrios 2004: 72), hace muy difícil en nuestra opinión relacionarlos con unas estructuras de combustión que las fechas, de aceptar su validez, retrasan cerca de milenio y medio (recordemos, en torno a 3635-3377 cal. BC).

Nosotros, en realidad, no desmentimos que hubiera un lugar de hábitat previo, sencillamente planteamos que las cinco estructuras halladas en el atrio se debieran a actos ceremoniales vinculados a la propia naturaleza funeraria del sepulcro y no a una coyuntura adventicia previa a su erección. Por el contrario, sí creemos más correcto conectar el proceso de condenación del monumento con la ampliación del túmulo y la colmatación de ese sistema de acceso mediante una única capa desde el suelo (mientras el resto del túmulo estaba constituido por cinco capas alternas de tierra y piedras).

\section{EN TORNO A LA DINÁMICA SEPULCRAL CAMERANA}

Los megalitos de Cameros son espacios funerarios de gran complejidad. Su carácter deviene de cambios en el uso del espacio, en el reclutamiento de los inhumados, en la introducción de los de- 
pósitos materiales e incluso en la interpretación del lugar durante su periodo de uso. Éste no es el lugar para tratar de esbozar pautas concretas de uso funerario de las sepulturas estudiadas, configuradas a base de pinceladas más o menos firmes en las páginas precedentes. En cambio tal vez lo sea para valorar los principales episodios que parecen marcar la vida de los megalitos cameranos, desde su concepción primigenia a su último empleo como espacios funerarios.

\subsection{Estratos previos o subtumulares}

El reconocimiento de estratos subtumulares ha conformado tradicionalmente la base empírica para proponer la fidelidad en la reiterada ocupación de determinados parajes. Esta circunstancia ha llevado a ciertos autores a "suponer un cambio en la ocupación de esos territorios que en el Mesolítico previo serían de habitación y explotación económica, y que coincidiendo con la neolitización y tal vez con cambios climáticos, decaen como preferencia habitacional y se transforman en el lugar de residencia de los antepasados que allá permanecerán en la perdurable tumba dolménica, significando la posesión del territorio" (Andrés 2009: 18).

Otros investigadores aducen, en cambio, que en ciertos casos "sea la implantación de sepulcros funerarios sobre áreas funerarias anteriores lo que los origine" (López de Calle e Ilarraza 1997: 316), lo que, en nuestra opinión, cobra pleno sentido en la estación megalítica de Cameros. En Collado del Mallo el hallazgo de un empedrado infrayacente al túmulo y corredor bajo el que aparecieron restos humanos asociados a elementos neolíticos ha sugerido a los investigadores que hubiera un área funeraria previa a la erección del sepulcro. Del mismo modo, bajo el túmulo de Collado Palomero I se recogieron restos de fauna y cerámicas que bien podrían ser testigo de otra "habida cuenta de las condiciones poco propicias para el asentamiento del lugar" (López de Calle e Ilarraza 1997: 316).

\subsection{Implantación y arquitectura}

En su diversidad, los megalitos surgirán donde y cuando sean posibles y necesarios. Explicar su proceso de adopción y adaptación en La Rioja exige conceder el protagonismo a la difusión cultural, en "un compromiso razonable entre la impregnación de la idea dolménica y su realización física, la cual dependerá de sus condicionantes autónomos" (Andrés 1997: 434). Estos condicionantes quedan materializados en la variabilidad estructural de los monumentos, donde se dan soluciones tan variadas como dólmenes simples (Fuente Morena), de corredor (Collado del Mallo), bicamerales (Peña Guerra II) y con atrio (Collado Palomero I).

En cualquier caso, y pese a que ignoremos las razones concretas por las que aquellas gentes decidieron erigir un monumento 'no perecedero' y utilizar un diseño específico, una idea común debió subyacer, posiblemente una creencia religiosa tal vez ligada a una referencia astral, dada la normalizada orientación de los dispositivos (Andrés 2009: 18).

\subsection{La inhumación y sus sistemas}

No arriesgaríamos demasiado si dijéramos que la inhumación primaria parece ser el modo dominante en el periodo de uso 'normativo', esto es, durante el Neolítico final y el Calcolítico inicial. Ello no implica negar la existencia de otros sistemas más elaborados, que pudieran corresponderse con depósitos secundarios (como el de Fuente Morena), cuando la sobrerrepresentación de piezas 'nobles' y el déficit de otros segmentos menos representativos del esqueleto son acusados.

También parece ser común en momentos antiguos el hallazgo de 'nidos de cráneos' y haces de huesos largos en ciertos lugares perimetrales de los sepulcros (cámara secundaria de Peña Guerra II, Collado del Mallo). Este gesto habitual en dólmenes del entorno (Múgica y Armendáriz 1991; Narvarte 2005) puede entenderse como resultado de despejes para favorecer el tránsito por la cámara y habilitar espacio para nuevos enterramientos o quizá de otras labores de trasfondo más ideológico que práctico. Las prácticas destinadas al aprovechamiento espacial nos permitirían plantear que se hicieran limpiezas y mondas con el mismo objetivo en las tumbas donde, a pesar de las irregularidades en el perfil osteológico, se documenta multitud de huesos pequeños, en general, de todos los segmentos que 
componen el esqueleto humano (Peña Guerra II, Collado del Mallo). Sin embargo, la disparidad porcentual entre diferentes huesos puede ser explicada asimismo por una conservación diferencial debida a la propia consistencia del hueso, a factores tafonómicos, a la acción de clandestinos o incluso al azar. En cualquier caso, si se hicieron labores de limpie$\mathrm{za}$, parece que no fueron demasiado sistemáticas.

Finalmente, hay gestos y modificaciones de origen antrópico que alteran la apariencia de los huesos. Destacan el empleo del fuego y del ocre en las sepulturas. En la estación camerana las cremaciones podrían estar relacionadas en la práctica totalidad de los casos con depósitos en plusieurs temps (Collado del Mallo, Collado Palomero I). En cambio las impregnaciones de ocre, de aceptar su naturaleza antrópica, podrían estar vinculadas a la conservación de los cuerpos por sus cualidades profilácticas, sin descartar otros posibles trasfondos simbólicos.

\subsection{Finalizaciones de ciclo}

Los enlosados pétreos que separan los diferentes niveles de inhumación en Peña Guerra II y Collado del Mallo resultan complejos de interpretar a este respecto. En rigor ni siquiera sabemos si los responsables de disponer estas capas desean cerrar un ciclo (Narvarte 2005: 217) o, por el contrario, abrir uno nuevo (Pérez Arrondo 1987: 166). Lo dilatado del uso megalítico hace que no tengan por qué ser necesariamente los mismos. No obstante la mayoría de los autores parece coincidir, como nosotros, en que estas actuaciones expresan el deseo de 'protección' de los restos por parte de sus contemporáneos (López de Calle e Ilarraza 1997: 313).

Aceptando esta hipótesis, lo más probable es que estas soluciones tuvieran un origen esencialmente práctico, ligado al aumento de la capacidad del sepulcro a través de reorganizaciones, de puntuales limpiezas o del propio arreglo estructural. Solo con el tiempo alcanzarían un carácter simbólico (Narvarte 2005: 307-308).

\subsection{Clausuras}

La compleja construcción y secuencia de gestos funerarios evidenciada en los sepulcros cameranos suele ir seguida con frecuencia de la sorprendente destrucción intencionada de los mismos. En Collado Palomero I la clausura conlleva, como ya se ha mencionado, "el cubrimiento total del edificio, incluido naturalmente el atrio, con sus tres hogares y con la pequeña estructura que contenía restos humanos" (López de Calle e Ilarraza 1997: 317). Otras veces, sin embargo, estas mismas zonas son inhabilitadas mediante soluciones que 'impermeabilizan' la cámara respecto al espacio de acceso. Así en Collado del Mallo el corredor estaba absolutamente enmascarado por un potente empedrado. Finalmente, en el sepulcro bicameral de Peña Guerra II, la cámara secundaria o excéntrica fue rellenada con tierra apelmazada quedando oculta en el túmulo mediante la colocación de grandes piedras en superficie. La inhabilitación fue tan efectiva que la cámara "probablemente pasó desapercibida para los últimos ocupantes del sepulcro ya que no se recogieron elementos recientes dentro de sus límites" (López de Calle e Ilarraza 1997: 313).

Es posible que esta a priori inesperada y premeditada inhabilitación del espacio funerario tenga su explicación en una 'interrupción' en el uso de los lugares megalíticos. Una ruptura que podría encontrar respuesta en factores si no demográficos, al menos ideológicos, plasmados en cambios en el comportamiento funerario. En efecto, sólo hace falta atender a las nuevas formas dolménicas que aparecen en Navarra (Álvarez 2006) o al uso de nuevos espacios sepulcrales (cuevas, abrigos, fosas, ...) (FernándezCrespo 2010), para comprender que el Calcolítico inicial del Valle del Ebro es un periodo de gran efervescencia poblacional y variabilidad funeraria.

\subsection{Reutilizaciones}

Desde el Calcolítico pleno y final la utilización dolménica en el Valle Medio del Ebro parece por lo general decaída. Al igual que en gran parte de Europa, se empieza a recuperar la forma de los enterramientos individuales, en general asociados al campaniforme. En este contexto, emerge sin embargo un curioso fenómeno de reutilización de dólmenes antiguos pese a haber sido clausurados, abandonados o destruidos hace tiempo, conformando una reinterpretación no forzosamente ajustada al 'mensaje' megalítico original (Delibes 2010: 46). Tales reocupaciones son un hecho claro en Peña Guerra II (nivel superior de la cámara 
principal) y Collado Palomero I (nivel A1), donde se hallaron, respectivamente, tres y nueve sujetos en total desconexión y acompañados de un interesante ajuar campaniforme.

Así las cosas y pese a los pocos casos bien documentados, son llamativos el desorden y los anómalos perfiles osteológicos en estos niveles. En ciertos contextos podrían inculparse a actividades clandestinas (Peña Guerra II), pero en otros (Collado Palomero I) parecen responder a procedimientos verdaderamente sepulcrales, dejando la puerta abierta a suponer una gran variabilidad en las formas de deposición tardías. Este hallazgo vendría así a sumarse a otros indicios peninsulares de enterramientos secundarios (como los de la necrópolis toledana de Valle de las Higueras y, tal vez, los de la fosa abulense de Valdeprados), "contribuyendo a relativizar la hipótesis de que el ritual campaniforme implica un depósito único y definitivo para los huesos de los líderes, que no son descarnados, ni trasladados" (Bueno et al. 2005: 78).

Al mismo tiempo, las diversas inhumaciones presentes en estos niveles, algunas infantiles como ha revelado el estudio antropológico, invitan a pensar que estos enterramientos hicieran hincapié, más que en la propia individualidad o posición social, en la importancia de la estirpe o de la familia, para establecer un vínculo -real o no- con los antiguos moradores (Andrés 2005: 261-262).

\section{CONCLUSIONES}

El análisis arqueoantropológico realizado sobre las sepulturas megalíticas cameranas de Peña Guerra II, Collado del Mallo, Fuente Morena y Collado Palomero I ha permitido la detección de gestos y comportamientos funerarios realmente diversos. Los meticulosos ordenamientos, las posibles mondas, los potenciales paquetes secundarios, cremaciones depósitos de ocre invitan a suponerlos beneficiarios de un ritual más elaborado que el sugerido por la literatura tradicional, pese a que la inhumación primaria se propone como el modo funerario predominante. Si a ello le sumamos la aparente complejidad de sus arquitecturas y secuencias funerarias, las cuales distan mucho de ser semejantes en los casos estudiados, se hace necesario entender estas estructuras como sepulturas dinámicas y polisémicas.
A pesar de esta heterogeneidad, parece que el espíritu 'colectivizador' que los primeros enterramientos evocaban en cierta medida, dio paso con el tiempo a formas de racionalidad diferentes (de ahí los diversos arreglos, finalizaciones de ciclo y clausuras) amparadas por nuevas necesidades, pasando en última instancia a ser concebidos y reutilizados como potenciales instrumentos legitimadores de poder.

\section{AGRADECIMIENTOS}

A los Dres. Ignacio Barandiarán y Concepción de la Rúa, co-directores de la Tesis Doctoral (véase n. 2), de la cual deriva este artículo, su asesoramiento y constante apoyo. Al Dr. Carlos López de Calle su buena disposición y amabilidad a la hora de facilitarnos el acceso y la consulta de su Tesis Doctoral y del material gráfico a ella asociado (véase n. 1).

Al Ministerio de Educación y Ciencia (HUM2005-04236; HAR2011-26956), al Gobierno Vasco (POS_2013_1_147; POS_2014_2_24) y a la Universidad del País Vasco (UFI 11/09) la financiación que ha permitido desarrollar esta investigación.

Por último, a los SGIker (UPV/EHU, MICINN, GV/EJ, FSE) y, en especial, al Dr. Alfredo Sarmiento, por el apoyo técnico y humano en el análisis por Espectroscopía Raman.

\section{BIBLIOGRAFÍA}

Álvarez, E. 2006: "Percepción y reutilización de los monumentos megalíticos durante la Prehistoria reciente: el caso de Navarra". Cuadernos de Arqueología de la Universidad de Navarra 14: 117-150.

Andrés, M. T. 1997: "Fases de implantación y uso dolménico en la Cuenca Alta y Media del Ebro". En A. Rodríguez Casal (ed.): O Neolítico Atlántico e as orixes do Megalitismo (Santiago de Compostela 1996): 431-444. Santiago de Compostela.

Andrés, M. T. 2005: Concepto y análisis del cambio cultural: su percepción en la materia funeraria del Neolítico y Eneolítico. Monografías Arqueológicas 42. Dpto. de Ciencias de la Antigüedad de la Universidad de Zaragoza. Zaragoza.

Andrés, M. T. 2009: "Comportamiento funerario en el Neolítico y Eneolítico: sociedad e ideología”. En J. 
Santos (ed.): Los tiempos antiguos en los territorios pirenaicos. Universidad del País Vasco. VitoriaGasteiz: 11-36.

Barrios, I. 2004: El yacimiento de Cueva Lóbrega (Torrecilla de Cameros, La Rioja): una visión acerca del Neolítico y la Edad del Bronce en el área occidental del Sistema Ibérico. Instituto de Estudios Riojanos. Logroño.

Bellido, A. y Ascensión, J. L. 1996: "Megalitismo y rituales funerarios". En T. Chapa y M. A. Querol (eds.): Homenaje al profesor Manuel FernándezMiranda. Complutum Extra 6 (1), Universidad Complutense. Madrid: 141-152.

Beguiristain, M. A. 2007/08: "Un singular acondicionamiento del espacio interno en el dolmen de Aizibita (Cirauqui, Navarra)". Veleia 24/25: 703-721.

Behrensmeyer, A. K. 1978: "Taphonomic and ecologic information from bone weathering". Paleobiology 4: $150-162$.

Bocquentin, F. 2003: Practiques funéraires, paramètres biologiques et identités culturelles au Natufien: une analyse archéo-anthropologique. Tesis Doctoral. Université de Bordeaux I. Burdeos. http://grenet. drimm.u-bordeaux 1.fr/pdf/2003/BOCQUENTIN_ FANNY_2003.pdf (consulta 23-VIII-2014).

Botella, M.; Alemán, I. y Jiménez-Brobeil, S. A. 2000: Los huesos humanos, manipulaciones y alteraciones. Bellaterra. Barcelona.

Bueno, P.; Barroso, R. y Balbín, R. de 2005: "Ritual campaniforme, ritual colectivo: la necrópolis de cuevas artificiales de Valle de las Higueras (Huecas, Toledo)". Trabajos de Prehistoria 62 (2): 67-90.

Buikstra, J. E. y Ubelaker, D. H. (eds.) 1994: Standards for data collection from human skeletal remains, Proceedings of a Seminar at the Field Museum of Natural History, organized by J. Haas. Arkansas Archaeological Survey Research Series 44. Arkansas Archaeological Survey Press. Fayetteville.

Canci, A. y Minozzi, S. 2005: Archeologia dei resti umani. Dallo scavo al laboratorio. Carocci. Roma.

Chambon, Ph. 2003: Les morts dans les sépultures collectives néolithiques en France. Du cadavre aux restes ultimes. XXXV Supplément à Gallia Préhistoire, CNRS éditions. París.

Clottes, J. 1977: "Le mégalithisme en Quercy". L'Architecture megalithique. Actes du Colloque du

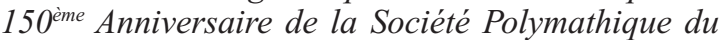
Morbihan (Vannes 1977): 49-70. Vannes.

Crubézy, E.; Duday, H.; Sellier, P. y Tillier, A. M. 1990: "Avant-Propos Paléoanthropologie et Archéologie de la mort: un dialogue vivant". Bulletins et Mémoires de la Société d'Anthropologie de Paris II (3-4): 5-12.

Delibes, G. 2010: "La investigación de las sepulturas colectivas monumentales del IV milenio a. C. en la Submeseta norte española. Horizonte 2007". En J. Fernández-Eraso y J. A. Múgica (eds.): $A c-$ tas del Congreso Internacional sobre Megalitismo y otras manifestaciones funerarias contemporáneas en su contexto social, económico y cultural (Beasain 2007). Munibe supl. 32. Sociedad de Ciencias Aranzadi. San Sebastián: 12-56.

Delibes, G.; Benet, N.; Pérez, R. y Zapatero, P. 1997: "De la tumba dolménica como referente territorial al poblado estable: notas sobre el hábitat y las formas de vida de las comunidades megalíticas de la Submeseta norte". En A. Rodríguez Casal (ed.): $O$ Neolítico Atlántico e as orixes do Megalitismo. Actas do Congreso Internacional (Santiago de Compostela 1996): 779-808. Santiago de Compostela.

Duday, H. 2005: "L'Archéothanatologie ou l'Archéologie de la mort". En O. Dutour, J. J. Hublin y B. Vandermeersch (eds.): Objets et Méthodes en Paléoanthropologie. Comité des Travaux Historiques et Scientifiques. París: 153-215.

Duday, H.; Courtaud, P.; Crubézy, E.; Sellier, P. y Tillier, A. M. 1990: "L'Anthropologie de 'terrain': reconnaissance et interprétation des gestes funéraires". Bulletins et Mémoires de la Société d'Anthropologie de Paris 2: 29-50.

Fernández-Crespo, T. 2010: "Caracterización antropológica y tratamiento funerario de las poblaciones del Neolítico a la Edad del Bronce en la comarca de la Rioja: estado de la cuestión". En J. Fernández-Eraso y J. A. Múgica (eds.): Actas del Congreso Internacional sobre Megalitismo y otras manifestaciones funerarias contemporáneas en su contexto social, económico y cultural (Beasain 2007). Munibe supl. 32, Sociedad de Ciencias Aranzadi. San Sebastián): 414-424.

Fernández-Crespo, T. y de la Rúa, C. 2015: "Demographic evidence of selective burial in megalithic graves of northern Spain". Journal of Archaeological Science 53: 604-617.

Hummel, S.; Schutkowski, H. y Herrmann, B. 1988: "Advances in cremation research". Notes et monographies techniques 24: 177-194.

López de Calle, C. 1992: "Tratamientos sepulcrales y presepulcrales de restos óseos en los yacimientos megalíticos de Cameros". Estrato 4: 35-41.

López de Calle, C. 1994: "Caracteres arquitectónicos y restos materiales del sepulcro megalítico de Collado del Mallo (Trevijano). Campaña de 1994". Estrato 6: 9-15.

López de Calle, C. 2002: "Huesos quemados, hogares y sepulcros incendiados. El fuego en los sepulcros monumentales de Cameros". En M. Rojo y M. Kunst (eds.): Sobre el significado del fuego en los rituales funerarios del Neolítico. Studia Archaeologica 91, Universidad de Valladolid. Valladolid: 232-152.

López de Calle, C. e Ilarraza, J. A. 1997: "Condenaciones y remodelaciones. Una respuesta a las estratigrafías de los sepulcros de Cameros". En R. de Balbín y P. Bueno (eds.): Actas del II Congreso de Arqueología Peninsular. Neolítico, Calcolítico y Bronce (Zamora 1996) II: 309-321. Zamora.

López de Calle, C.; Iriarte, M. J. y Zapata, L. 2001: "Análisis paleoambientales del dolmen de Collado del Mallo (Trevijano, La Rioja). Viabilidad y trabas 
de la paleoecología vegetal en estructuras dolménicas". Zubía Monográfico 13: 65-96.

López de Calle, C. y Tudanca, J. M. 2005: "El Megalitismo". En J. G. Moya y B. Arrúe (eds.): Historia del Arte en La Rioja: de la Prehistoria a la Antigüedad Tardía. Fundación Caja Rioja. Logroño: 27-44.

Múgica J. A. y Armendáriz, A. 1991: "Excavaciones en la estación megalítica de Murumendi (Beasain, Guipúzcoa): túmulos de Trikuaizti I y II y Larrarte". Munibe (Antropologia-Arkeologia) 43: 105-165.

Narvarte, N. 2005: Gestión funeraria dolménica en la Cuenca Alta y Media del Ebro: Fases deocupación y clausuras. Historia-Arqueología 16. Instituto de Estudios Riojanos. Logroño.

Pérez Arrondo, C. L. 1987: "El fenómeno megalítico en la margen derecha del Ebro: La Rioja. Estado de la cuestión y principales problemas". En El Megalitismo en la Península Ibérica. Ministerio de Cultura. Madrid: 159-180.
Pérez Arrondo, C. L. y López de Calle, C. 1988: “Excavaciones de la zona megalítica de Viguera. Collado Palomero I. Campañas 1986 y 1987’. Brocar 14: 31-52.

Silva, A. M. 1997: "O Hipogeu de Monte Canelas I: contribuição da Antropologia de campo e da Paleobiologia na interpretação dos gestos funerários do IV e III milénios a. C.”. En R. de Balbín y P. Bueno (eds.): II Congreso de Arqueología Peninsular. Neolítico, Calcolítico y Bronce (Zamora 1996) II: 241-248. Zamora.

Stodder, A. L. W. 2008: "Taphonomy and the Nature of Archaeological Assemblages". En M. A. Katzenberg y S. R. Saunders (eds.): The Biological Anthropology of the human skeleton. Wiley-Liss. Nueva York: 71-114.

White, T. D. y Folkens, P. A. 2005: The Human Bone Manual. Academic Press. San Diego. 